\title{
Maleic anhydride grafting on EPDM rubber in the melt
}

\author{
A. J. Oostenbrink and R. J. Gaymans* \\ Twente University of Technology, PO Box 217, 7500 AE Enschede, The Netherlands \\ (Received 24 October 1990; revised 21 June 1991)
}

\begin{abstract}
The grafting of maleic anhydride on a EPDM rubber was studied with a twin screw extruder. The effect of barrel temperatures, throughput, maleic anhydride concentration and peroxide concentration [ bis ( $t$-butyl peroxy isopropyl)benzene] on the degree of grafting and melt viscosity was studied. The maleic anhydride concentration was determined by potentiometric titration and a correlation was made with quantitative i.r. analysis.
\end{abstract}

(Keywords: EPDM; maleic anhydride; grafting)

\section{INTRODUCTION}

The maleic anhydride (MAN) modification of rubbers is of interest as a way of compatibilizing the rubber with polyamides in the formation of toughened blends $s^{1-3}$. With MAN modification the rubber can react with the polyamide forming a graft copolymer bridging the polyamide-rubber interphase. In this way the interfacial tension is strongly reduced. With a lower interfacial tension a finer dispersion can be obtained ${ }^{2,4}$. Particular EPDM and EPR rubbers are used as the toughening phase ${ }^{5}$ and for this purpose these elastomers are modified with MAN.

MAN can be grafted onto the rubber in a solution process $^{6}$ or in the melt ${ }^{7-9}$. For the grafting of MAN a number of reactions have been proposed ${ }^{7}$. The initiation of the grafting can be either by peroxide decomposition or by thermal-mechanical radical formation. The radicals abstract hydrogen from the polymer chain. MAN molecules may add to these macroradicals thus forming MAN radicals covalently bonded to the rubber. These rubber-grafted MAN (g-MAN) radicals have a low tendency to homopolymerize and the radical site is transferred to an adjacent polymer chain. The radical may also terminate. Gaylord et al. studied the grafting of MAN on EPR rubber in the melt with a Brabender mixer at high MAN concentrations (5-20\%) and suggested that grafting of EPR rubber with MAN under conditions at which peroxides have short half-lives results in the formation of reactive MAN species ${ }^{7}$. These excited MAN species increase the radical generation on the polymer beyond that attributable to the radicals from peroxide. As well as the grafting reaction both crosslinking or chain scission of the polymer might take place.

Recently $\mathrm{Hogt}^{9}$ showed by reaction blending EPDM/ MAN in the presence of a peroxide (Triganox 101) with a Haake laboratory twin screw extruder that the efficiency of the grafting reaction at low MAN was independent of the type of EPDM used and was $\sim 35 \%$.

*To whom correspondence should be addressed

0032-3861/92/143086-03

(C) 1992 Butterworth-Heinemann Ltd.

3086 POLYMER, 1992, Volume 33, Number 14
Grafting at high MAN concentrations was limited by the solubility of MAN in the EPDM.

This report describes the modification of an EPDM rubber with MAN in a twin screw extrusion process.

\section{EXPERIMENTAL}

The functionalization of EPDM with MAN is carried out in a Berstorff $25 \mathrm{~mm}$ co-rotating twin screw extruder. The EPDM (Keltan 740, DSM), had an ethylene/propylene/dicyclopentene content of $65 / 34 / 1$. The peroxide, [bis(t-butyl peroxy isopropyl)benzene] (Perkadox 14, Akzo), has $E_{1 / 2}$ values of $5 \mathrm{~min}$ at $175^{\circ} \mathrm{C}$ and $10 \mathrm{~s}$ at $210^{\circ} \mathrm{C}$. The MAN is supplied as a $50 / 50$ master batch in polyethylene (Nourymix MA 903, Akzo). All the materials were starved fed to the first section of the extruder. A nitrogen atmosphere was maintained over the reaction mixture. By the last port, vacuum was applied to remove free MAN and other volatile components. The standard extrusion conditions were: throughput $1 \mathrm{~kg} \mathrm{~h}^{-1}$; rotor speed $150 \mathrm{rev} \min ^{-1}$; and the temperature settings were $140,155,170,170,170$, 170 and $195^{\circ} \mathrm{C}$. Under these conditions the residence time was $5 \mathrm{~min}$.

The amount of g-MAN was determined by potentiometric titration on vacuum dried samples in 1,2dichloroethane/ethanol $(9: 1)$, dissolved at $60^{\circ} \mathrm{C}$ and titrated with a $0.1 \mathrm{M} \mathrm{KOH}$ solution in t-butanol.

I.r. analysis was carried out on thin melt pressed films which had been dried in a vacuum oven $\left(1\right.$ day at $\left.110^{\circ} \mathrm{C}\right)$, and the MAN carbonyl peak $\left(1785 \mathrm{~cm}^{-1}\right)$ to the $\mathrm{C}-\mathrm{H}$ stretch peak $\left(715 \mathrm{~cm}^{-1}\right)$ ratio $(\lambda)$ determined.

\section{RESULTS}

Correlation between end group and i.r. analyses

Quantitative i.r. analysis of functionalized rubber is a far more simple, faster and cheaper method than potentiometric titration. In Figure $l$ the g-MAN, as determined by titration, is given as a function of $\lambda$, the 


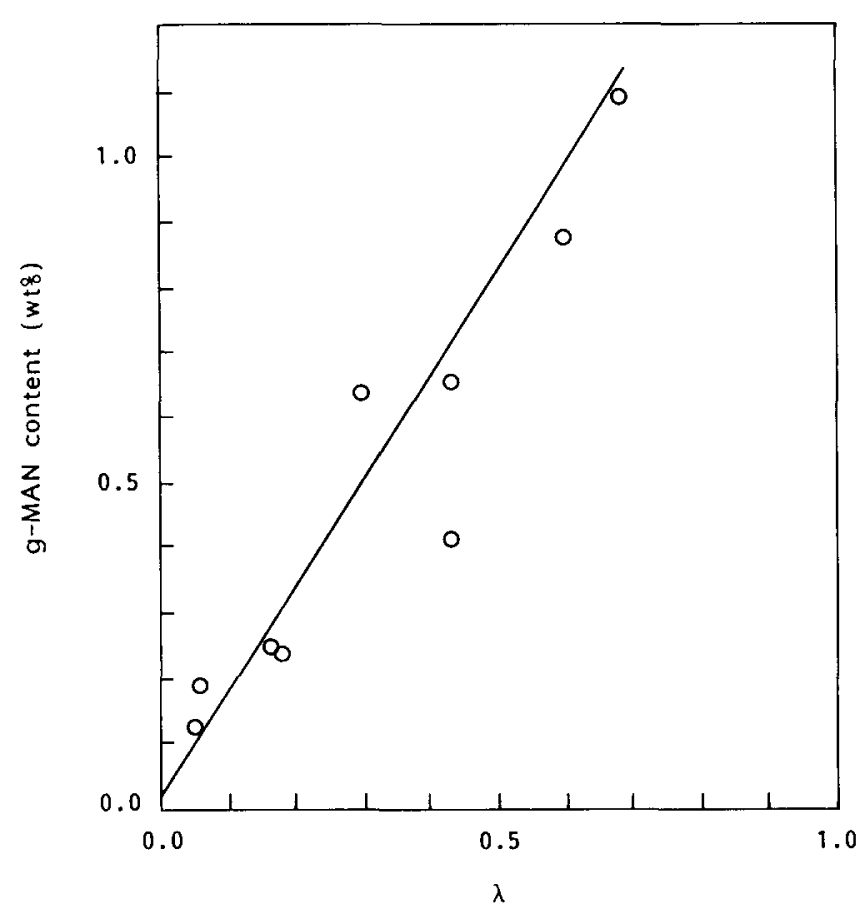

Figure 1 g-MAN content from potentiometric titrations versus $\lambda\left(1785 / 715 \mathrm{~cm}^{-1}\right)$ from i.r. analysis

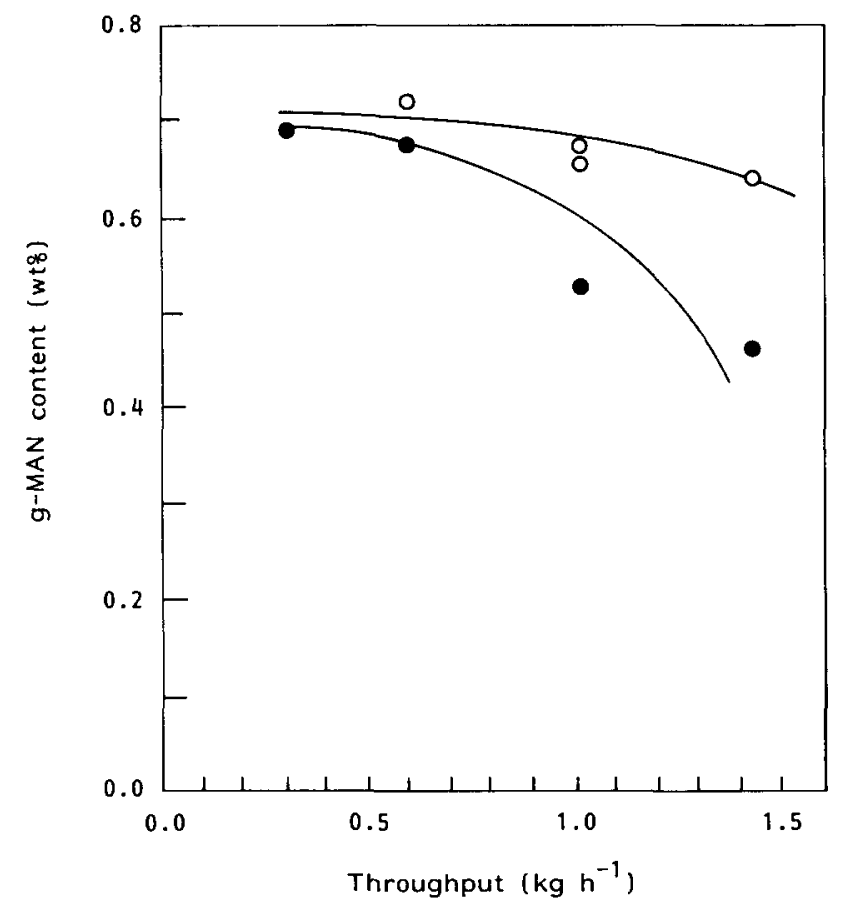

Figure 2 Effect of throughput rate at low $\left(140-195^{\circ} \mathrm{C}, \mathrm{O}\right)$ and high $\left(140-220^{\circ} \mathrm{C}\right.$, ) set barrel temperatures (added MAN $=2 \mathrm{wt} \%$; Perkadox $14=0.025 \mathrm{wt} \%$ )

quotient of the 1785 and $715 \mathrm{~cm}^{-1}$ absorbance peaks. The relationship is linear and the slope is 1.6.

\section{Processing variables}

The effect of throughput was studied at two barrel temperature settings (Figure 2). With the relative low settings $\left(140-195^{\circ} \mathrm{C}\right)$ the mass temperature in the die was $225^{\circ} \mathrm{C}$ and the MAN content in the EPDM was found to be hardly dependent on the throughput $(0.7 \%)$.
With the higher settings $\left(140-220^{\circ} \mathrm{C}\right)$ the mass temperature in the die was $260^{\circ} \mathrm{C}$ and the MAN concentration decreased with throughput. At very low throughputs $\left(300 \mathrm{~g} \mathrm{~h}^{-1}\right)$ the MAN content was $0.7 \%$, and $0.46 \%$ at $1.5 \mathrm{~kg} \mathrm{~h}^{-1}$

The very fast decomposition of peroxide at higher temperatures $\left(t_{1 / 2}\right.$ at $\left.210^{\circ} \mathrm{C}=10 \mathrm{~s}\right)$ and the considerable heat build-up of the EPDM due to the processing mean that at the higher barrel temperatures the peroxide is active before the peroxide and the MAN have been dissolved in the EPDM. The result of this is a lower degree of grafting.

With all other experiments the specified lower temperature settings were used.

\section{Initiator concentration}

The effect of initiator concentration on the degree of grafting is given in Figure 3. Without initiator there is some thermal grafting $(0.1 \%$ g-MAN $)$. At higher temperatures the degree of the thermally activated grafting process is higher.

With increasing initiator concentration the g-MAN content increased strongly. The grafting efficiency increases from $5 \%$ without initiator to $60 \%$ with $0.05 \%$ initiator. From the initial slope it can be calculated that 20 MAN molecules are grafted per radical species. From this it can be concluded that the radical transfer reaction goes much faster than the termination reaction.

Rheology measurements showed that the melt viscosities of the functionalized rubbers increased with peroxide concentration. A EPDM-g-MAN made with $0.025 \mathrm{wt} \%$ Perkadox 14 and compared to a system made without Perkadox 14 showed that the melt viscosity increased over a wide shear rate range by $50 \%$.

\section{Initial MAN concentration}

As expected with increasing added MAN the g-MAN increased (Figure 4). However at very high concentrations

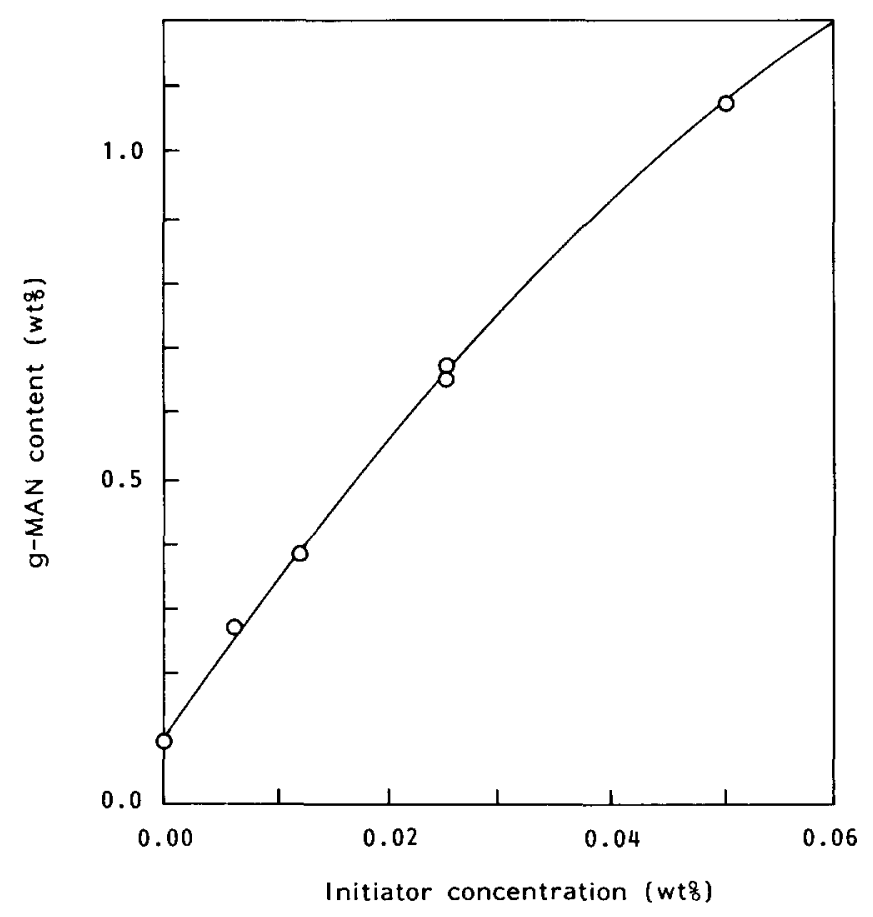

Figure 3 Influence of peroxide concentration on g-MAN content (added MAN $=2 \mathrm{wt} \%$ ) 


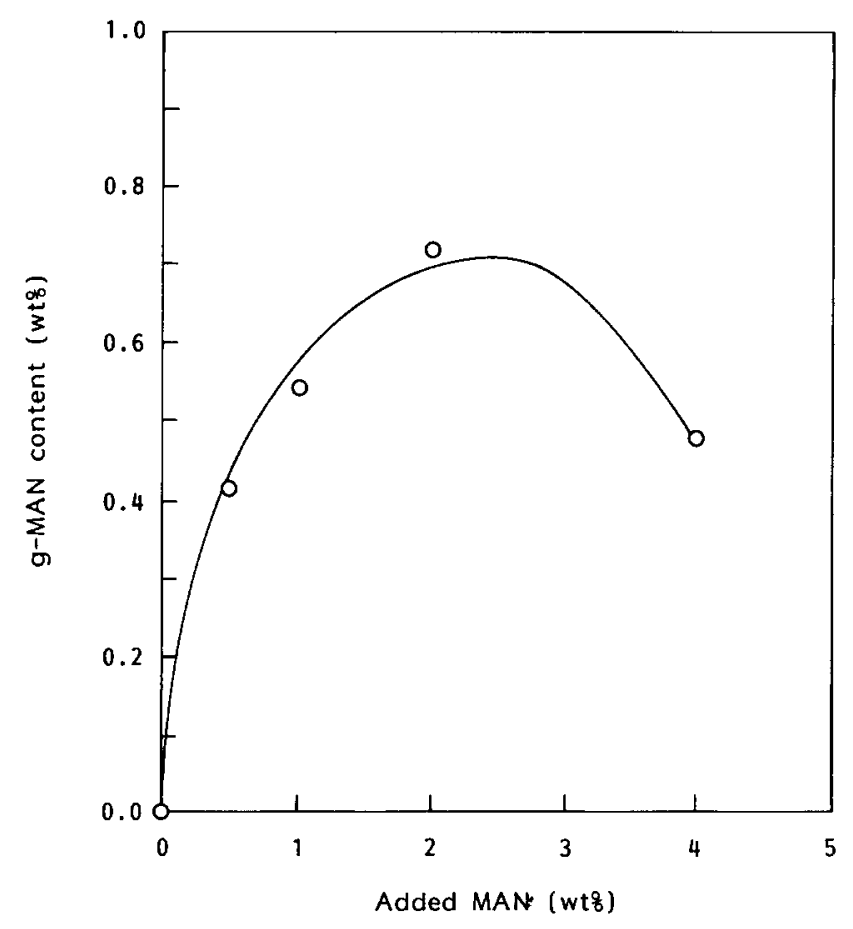

Figure 4 g-MAN content versus added MAN (Perkadox $14=0.025$ $w t \%)$

of added MAN (4\%) the g-MAN decreased again and the material was strongly discoloured. That an actual lowering of g-MAN was observed instead of a levelling off suggests a decrease in reactivity. In another experiment it was observed that the added MAN at these high concentrations did not dissolve completely, which means that two phases are present: an EPDM phase with some MAN and a separate MAN phase. In this two-phase system the initiator is partitioned between the phases. The initiator concentration in the EPDM plus MAN phase is lower now than in the other experiments and so less MAN is grafted. The initial slope in Figure 4 suggests that the grafting efficiency must be at least $60 \%$.

The melt viscosity of the functionalized rubber was found to be independent of g-MAN.

\section{CONCLUSIONS}

Functionalization of EPDM by grafting with MAN in a twin screw extruder is possible. Without initiator it is a thermal grafting process and under the conditions studied the process has a low efficiency. With an initiator the grafting goes much better and conversions up to $60 \%$ are obtained and about 20 MAN molecules are grafted per radical species. At high added MAN not all the MAN is able to dissolve in the EPDM. A consequence of this two-phase system is that only part of the peroxide goes into the EPDM phase. As a result, the amount of g-MAN decreases.

\section{REFERENCES}

1 von Flexman, E. A. Kunststoffe 1979, 69, 172

2 Wu, S. Polym. Eng. Sci. 1987, 27, 335

3 Borggreve, R. J. M., Gaymans, R. J., Schuijer, J. and Ingen Housz, J. F. Polymer 1987, 28, 1489

4 Borggreve, R. J. M. and Gaymans, R. J. Polymer 1989, 30, 63

5 Borggreve, R. J. M., Gaymans, R. J. and Schuijer, J. Polymer 1989, 30, 71

6 Cimminio, S., D 'Orazio, L., Greco, R., Maglio, G., Malinconico, M., Martuscelli, E., Palumbo, R. and Ragoista, G. Polym. Eng. Sci. 1984, 24, 48

7 Gaylord, N. G., Metha, M. and Metha, R. J. Appl. Polym. Sci. $1987,33,2549$

8 Gaylord, N. G., Metha, R., Kumar, V. and Tazi, M. Polym. Prepr. 1987,565

9 Hogt, A. H. 'Proc. COMPALlOY '90', New Orleans, 1990 